\title{
THE INFLUENCE OF TRAIN RUNNING DIRECTION AND TRACK SUPPORTS POSITION ON THE BEHAVIOUR OF TRANSITION ZONES
}

\author{
Roberto Sañudo \\ Researcher, University of Cantabria, Spain \\ Marina Miranda \\ Lecturer, Edinburgh Napier University, United Kingdom \\ Valeri Markine \\ Assistant Professor, Delft University of Technology, the Netherlands \\ Luigi dell' Olio \\ Associate Professor, University of Cantabria, Spain
}

\section{SUMMARY}

Different types of track infrastructure can be found along railway lines. Separation zones between these different types of structures are the source of a lot of problems. Transition zones on a railway line represent a gradual solution for the problems between conventional railway structure and singular structures located at different points along the line. The different nature, positioning and geometry used with the materials generate changes in the stiffness on both sides of these singular zones leading to an increase in wear and a loss of geometry, with the associated maintenance costs.

This article describes the use of mathematical modelling to represent the behaviour of these zones as a function of train running direction and track supports. Available research into transition zones has not studied these separation points where high increases in load are generated for very short periods of time.

Finite elements are used to model two types of track (conventional ballasted track and slab track), using a vehicle to dynamically simulate the behaviour in these zones as a function of train running direction and the position of track supports.

The magnitudes analysed were the vertical stresses and the vertical displacements under the sleepers and the supports in both types of structure.

The results show increased stresses at the separation zone between both structures which varied in magnitude and position depending most of track supports' location than the train running direction.

Keywords: Track transition, train running direction, track supports, transient stresses, transient displacements, ballast track, slab track. 


\section{INTRODUCTION}

\subsection{Transition zones}

Track transitions are defined as necessary locations where the railway infrastructure changes the configuration of materials from conventional track or ballasted track. Gradual changes in material and geometry mean gradual changes in the performance of the track.

\subsection{Problems in the transition zones}

Track behaviour suddenly changes in these zones causing problems resulting mainly from two phenomena (Paixao, Fortunato et al. 2013):

1. Sudden changes in the vertical stiffness of the track, due to the use of materials with very different mechanical properties both in the superstructure and the infrastructure.

2. Differential settlement due to settlements in the foundations. Normally the track structures (Tunnels, viaducts) experience less settlement than that found in open track (embankments).

Both phenomena contribute to an increase in dynamic loads and therefore, greater damage caused to the structure. In the second case, deterioration in the support conditions could result in hanging sleepers and track deterioration increases. A summary of the most important causes can be found in (Nasarre 2007) and a description of the most important problems found in these zones is available in (Sañudo, Markine et al. 2011).

Different solutions exist for addressing the problems arising in transition zones by: (a) Acting on the infrastructure (b) Acting on the superstructure (c) Acting on both (Sañudo, dell'Olio et al. 2016)

\subsection{The influence of train running direction.}

Train running direction affects the behaviour of transition zones. Acting loads are not the same travelling in different directions and little bibliography is available on this subject.

The effect on the wheel loads and the acceleration registered in the axle box can be found in (Namura and Suzuki 2007) showing changes in the average acceleration in the axle box. Acceleration peaks over the ballast and variations in the loadings per wheel appear over slab track or ballasted track depending on the train running direction. Comparisons are made between measured and analytical results where a similar trend is found. All measurements were obtained from on board measurements (axle box).

This paper analyses vertical stresses and vertical displacements obtained at ballast level (under sleepers) and under the principal slab in slab track.

The deflection profile before and after a bridge is studied in ( $\mathrm{Li}$ and Davis 2005) and (Read and $\mathrm{Li}$ 2006). The maximum deflection is found to occur immediately before entering the bridge and after leaving it, just in ballast side. The track model is also studied and although 
there are sudden changes in the track modulus, no variations are found with respect to train running direction.

A train travelling at $20 \mathrm{Km} / \mathrm{h}$ from slab track to ballasted track is studied in (Sañudo, Markine et al. 2014) who found that the maximum stresses in the supports are located in the area of slab track.

After defining the transition zone and its importance as part of a railway network, a brief bibliographic review has evaluated previous work considering the influence of train running direction in a behavioural analysis. The following sections will describe the methodology followed, the models used, and the results obtained in this research. They will then be discussed before finalising the article with a summary of the most important conclusions drawn.

\section{METHODOLOGY}

The methodology followed was first used in (Sañudo, Markine et al. 2011) and consists of modelling the track and the vehicle using finite elements and simulating the movement of the train in one direction and the other. Knowledge about the geometric and mechanical characteristics of each and every material making up the structure of the track and the vehicle is a prerequisite for the work. A series of assumptions need to be considered:

- The structure is only subjected to vertical loads.

- The properties of the structure are symmetrical in the horizontal plane with respect to the axis of the track.

- The contributions of the axial forces in the underlaying layers have been neglected.

- The deflection length of the rigid layer is greater than the thickness of the rigid layer.

The structure is analysed numerically using the finite elements method (discrete displacements)(Zienkiewicz, Taylor et al. 1977, Kok 1995).

The transient vertical stresses and displacements in the ballast layer will be studied in the transition zone when a train passes in the two directions. The ballast is an element which may compromise the structural integrity of the track in these zones so pressure on the ballast will be kept below 300-500 KN/m² (Esveld 2001, Lichtberger 2011). Although the concrete in the slab track is a much more resistant element the structural integrity of the slab track still needs to be assessed by checking its bending stiffness. Only vertical displacements and vertical stresses have been analysed under track supports (under principal slab and sleepers).

\subsection{Track model}

The structure of the ballasted track was modelled as simple beams on an elastic foundation, whereas the slab track was modelled using two or more beams with elastic material between them. A $200 \mathrm{~m}$ long track was divided into $0.05 \mathrm{~m}$ long elements, including the rail, the pads, the fastenings and the lower layers, with the limit zone between slab track and ballasted track 
located at the $100 \mathrm{~m}$ mark. There is no transition considered between slab track (left) and ballast track (right), (see figure 1).

Fig. 1 - Track model used for this study. Slab track (left) and ballasted track (right). The train runs in each direction from one to the other.

The mechanical and geometrical properties of the elements used in the track model are defined in the following table.

\begin{tabular}{|c|c|c|c|c|c|c|c|c|c|c|c|c|c|}
\hline \multirow{2}{*}{ Rail / Units } & \multicolumn{2}{|c|}{$\begin{array}{c}\text { Direct } \\
\text { fastenings }\end{array}$} & \multicolumn{2}{|c|}{ Pads } & \multicolumn{2}{c|}{ Slab } & \multicolumn{3}{c|}{ Sleepers } & \multicolumn{2}{c|}{ Ballast } & \multicolumn{2}{c|}{ Elastic Bed } \\
\cline { 2 - 15 } & $\mathrm{K}$ & $\mathrm{C}$ & $\mathrm{K}$ & $\mathrm{C}$ & $\mathrm{E}$ & $v$ & $\mathrm{E}$ & $v$ & $\rho$ & $\mathrm{K}$ & $\mathrm{C}$ & $\mathrm{K}$ & $\mathrm{C}$ \\
\hline $\begin{array}{c}\text { UIC 60 } \\
\text { (Slab Track) }\end{array}$ & $3.3 \mathrm{E}+05$ & 40 & - & - & $3,5 \mathrm{E}+04$ & 0,2 & - & - & 2,4 & - & - & $2.4 \mathrm{E}+07$ & 200 \\
\hline $\begin{array}{c}\text { UIC 60 } \\
\text { (Ballast Track) }\end{array}$ & - & - & $10 \mathrm{E}+05$ & 35 & - & - & $8 \mathrm{E}+04$ & 0.2 & 2,5 & $2 \mathrm{E}+05$ & 80 & - & - \\
\hline
\end{tabular}

Table 1 - Mechanical properties used in the first simulation. Ballasted track and slab track. Units K (KN/m), C $(\mathrm{KN} \cdot \mathrm{s} / \mathrm{m}), \mathrm{E}\left(\mathrm{KN} / \mathrm{m}^{2}\right), \rho\left(\mathrm{Tn} / \mathrm{m}^{3}\right)$.

\begin{tabular}{|c|c|c|c|c|c|}
\hline Foundation Properties & E & Poisson v & $\boldsymbol{\rho}$ & $\begin{array}{c}\text { Width } \\
(\mathbf{m})\end{array}$ & Thickness (m) \\
\hline Under slab & $2.975 \mathrm{E}+04$ & 0.2 & 2.4 & 4.8 & 0.75 \\
\hline Under ballast & 80 & 0.3 & 2.0 & 5.2 & 0.6 \\
\hline Formation Properties & $\mathbf{K}$ & $\mathbf{C}$ & $\rho$ & & \\
\hline Same properties along the track & 1000000 & 200 & 1 & - & - \\
\hline
\end{tabular}

Table 2 -. Mechanical properties used for the track infrastructure in the first simulation.

Slab track consist on elastic pads with $33 \mathrm{KN} / \mathrm{mm}$ ballast track has been analysed with 100 $\mathrm{KN} / \mathrm{mm}$ pads. Concrete used in the principal slab of slab track is HA-35 whereas sleepers' concrete is special prestressed concrete $80 \mathrm{MPa}$.

\subsection{Vehicle model}

The vehicle consists of a model of suspended and non-suspended masses on a group of springs and shock dampers. The speed considered for the simulation was $50 \mathrm{~m} / \mathrm{s}(180 \mathrm{Km} / \mathrm{h})$. The vehicle used was a Thalys locomotive and the data used to define the geometry and the mechanical characteristics used in the simulation are presented in (Sañudo, Markine et al. 2011, Sañudo 2013). Figure 2 shows an scheme of spring and dampers in the vehicle model 
used in the simulations.

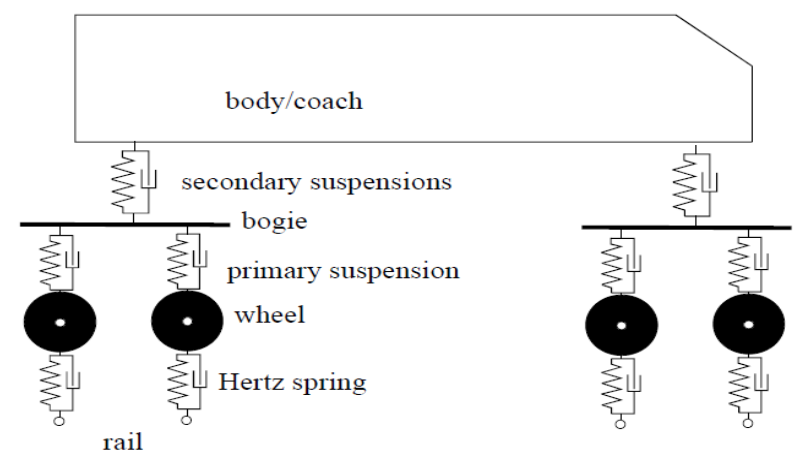

Fig. 2 - Vehicle model used in the simulation.

\subsection{Results}

A transient analysis in time domain were carried out by authors to study initial behavior on these areas. Only maximum values of displacements and stresses have been taken into account for the track supports. The vertical displacements under the main slab were found in the slab track zone and under the sleepers in the ballast area in the conventional track. The circulation of the train has been modelled travelling from slab track to ballasted track (left) and from ballasted track to slab track (right).

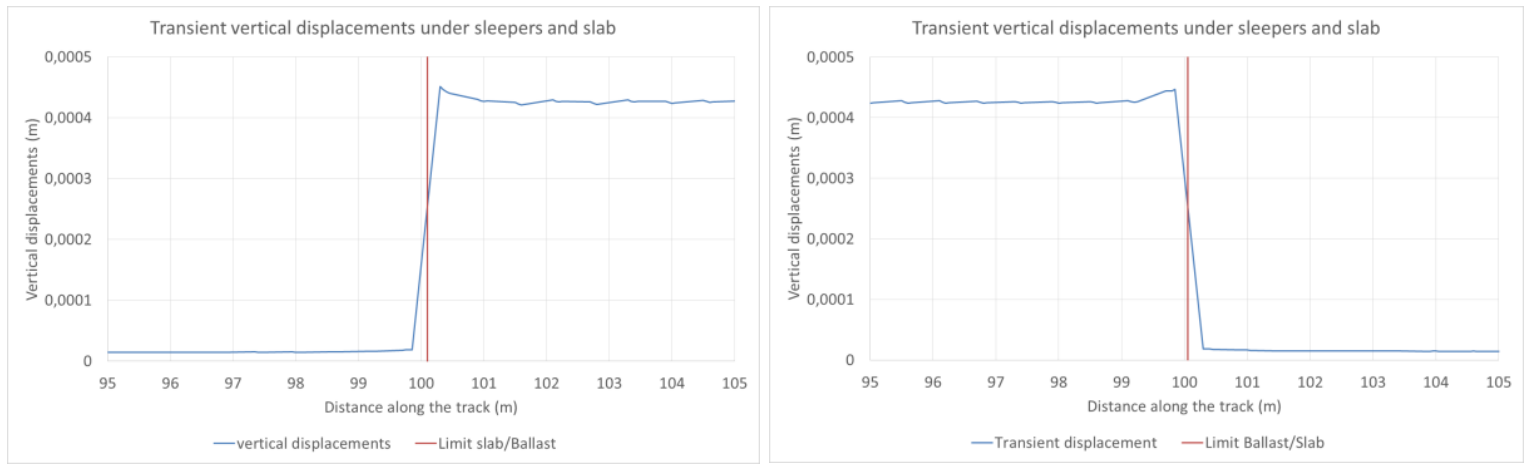

Fig. 3 - Vertical transient displacement, train travels from slab track to ballasted track (left).Train travels from ballasted track to slab track (right).

It can be seen that when the train runs from slab track to ballasted track the transient displacement immediately occurs after leaving the area of slab track, as shown in figure 3 (left). The displacements are considered in absolute values. The vertical displacement values are insignificant in the slab track zone and are below $0,2 \mathrm{~mm}$ in the ballasted zone, as can be seen in figure 3.

Figure 3 (right) shows the vertical displacements when the train circulates from ballasted track to slab track. The vertical displacements are below $0.45 \mathrm{~mm}$ and increase very slightly before entering the slab track zone where the displacements are found to be very small (less than $0,2 \mathrm{~mm})$.

An analysis of the stresses shows that if the train runs from slab track to ballasted track there is a slightly increase in stresses just after leaving the slab track zone which occurs in the 
ballasted. The values of the stresses experienced in the slab track zone are lower than 100 $\mathrm{KN} / \mathrm{m}^{2}$ (compression) (see figure 4, left). Immediately after the limit between the slab track and the ballasted track (now over the ballasted track), with general values under $300 \mathrm{KN} / \mathrm{m}^{2}$ in the ballasted area.

Figure 4 (right) shows the vertical stresses under the sleepers and the main slab in the slab track area when the train runs from ballasted track to slab track. The stresses seem to be smaller when the train approaches travelling from the ballasted track. These are then strikingly reduced in the slab track zone, from less than $300 \mathrm{KN} / \mathrm{m}^{2}$ to approximately 95 $\mathrm{KN} / \mathrm{m}^{2}$.
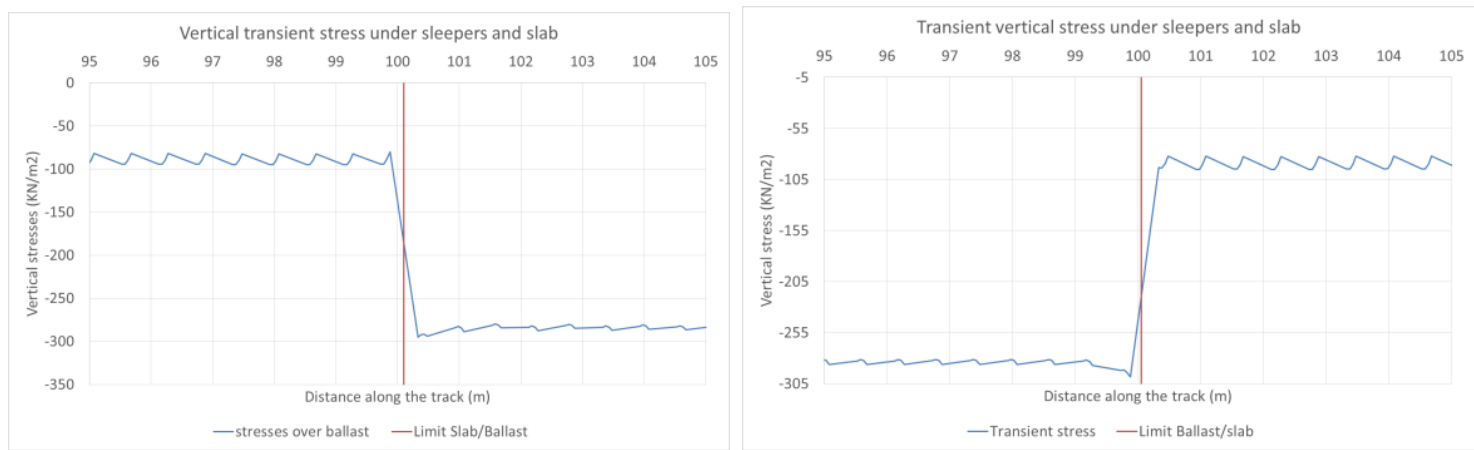

Fig. 4 - Vertical transient stresses. Train travels from slab track to ballasted track (left). Train travels from ballasted track to slab track (right).

If we choose the $300 \mathrm{KN} / \mathrm{m}^{2}$ as a limit, all obtained values go under this limit. The stresses reached in the slab are below its pressure resistance limits. The bending moments in the slab are due to the maximum forces generated and their spacing. Therefore, from a structural point of view the stresses are lower than the maximum allowed levels for both types of structure.

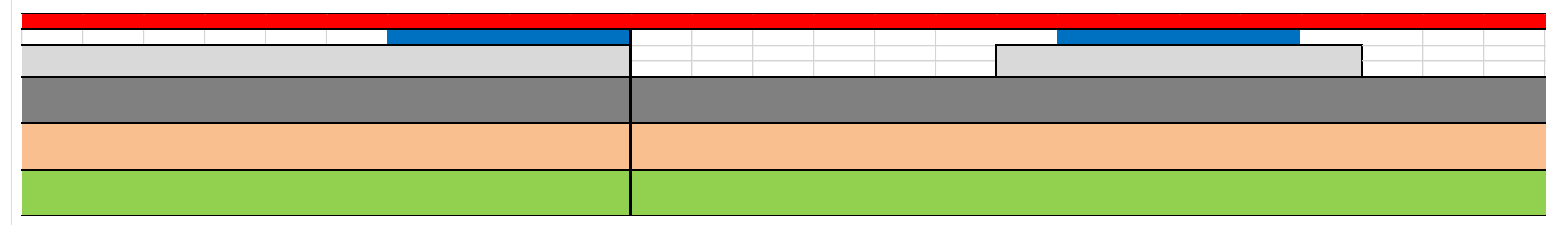

Fig. 5 - Position of track supports in separation between slab track (left) and ballast (right) track used for simulations in figures 6 and 7.

Authors analysed different materials and geometry at this location to smooth the transition between two areas (slab and ballast track). The figures 6 and 7 show some simulations which were carried out by authors for both running directions introducing new superstructure elements (additional rails and longer sleepers). If we compare both studies important conclusions can be obtained. Track supports' position is depicted in figure5.

In all figures vertical green line depict the separation point between slab and ballast track. Blue lines represent no transition case between slab track and ballast track for both running directions and red lines depict an initial solution of transition between slab track and ballasted track which consist on (additional rails and longer sleepers). Concrete used for sleepers and slab in this case is HP-40. Ballast and elastic bed properties are the same as 
table 1 .

Separation point between slab track and ballasted track and viceversa, in these new cases is located at element 700 . These figures show a $240 \mathrm{~m}$ long track with a separation between slab track and ballast track at $140 \mathrm{~m}$. The length of element discretization was 0,2 $\mathrm{m}$. Train properties was the same as figure 2 , but speed increases up to $320 \mathrm{Km} / \mathrm{h}$. Here the boundary limit configuration was different. Last support on slab track side was just at the end (see figure 5).

If we focus on no transition (the blue lines) follow the same trend as figures 3-4. The explanation for higher stresses is just because in these simulations layers under ballast and main slab have been neglected.

Figure 7 show vertical stresses under sleepers. If there is no transition (blue lines) we have the same trend as figure 4. If we make a transition with additional rails and longer sleepers (red lines) a peak just in the limit appears. This peak is locates within slab track side so ballast is not affected. A gradual change in transient vertical stresses and transient vertical displacements is created (red lines). The length of this gradual change depends on the length of track modifications. Train speed is another important variable to take into account.

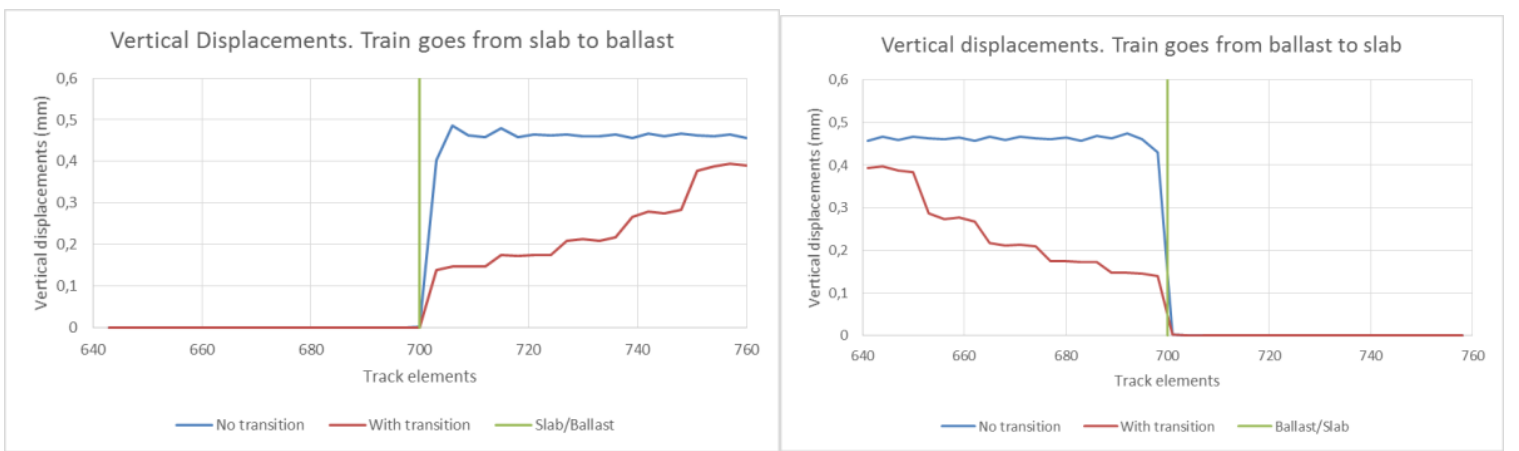

Fig. 6 - Vertical displacements. Train goes from slab track to ballast track (left) and from ballast to slab track (right). Materials and geometry are different from tables 1 and 2.

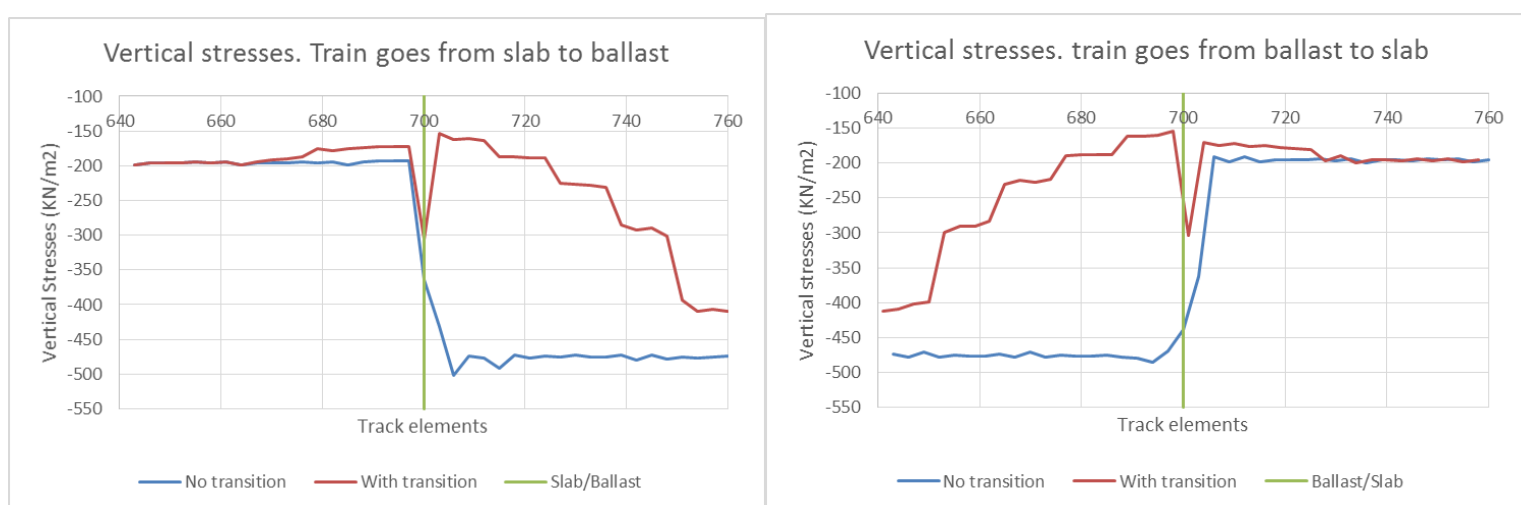

Fig. 7 - Vertical displacements. Train goes from slab track to ballast track (left) and from ballast to slab track (right). Materials and geometry are different from tables 1 and 2. 


\section{DISCUSSION}

An explanation and analysis of the results of this research follows below. As the study evaluated vertical stresses and displacements, the discussion will be divided into two parts:

- Transient vertical displacements study

- Transient vertical stresses study

\subsection{Transient vertical displacements}

As can be seen in figure 3 and figure 6 the transient vertical displacements are mostly the same when the train travels in one direction or the other. When the train travels from slab track to ballasted track a punctual increase in transient vertical displacement occurs just after slab track. Displacement here is slightly higher than punctual transient displacement in ballast side just before slab track (figure 3).

When train goes from ballast to slab there is another slightly increase in vertical displacement just after going in to the slab track. Last ballast sleeper experiment a little settlement. Assuming a good support and new track difference in transient displacement's values after and before are small. This small settlement can lead in hanging sleepers in a long term (a fatigue analysis will be necessary to determine this).

Difference in track stiffness induced by different track structure properties (see table 1 and table 2) from one point to other, makes this possible.

\subsection{Transient vertical stresses.}

Similarly, turning now to the transient vertical stresses, when the train travels from slab track to ballasted track an increase of more than $200 \mathrm{KN} / \mathrm{m}^{2}$ occurs in the stresses found in the ballasted zone. Highest vertical stresses is located at ballast side under $300 \mathrm{KN} / \mathrm{m}^{2}$. This value is below the maximum recommended for ballast (figure 4 left).

When the train travels from ballasted track to slab track a similar reduction in stresses is also generated just after the separation point. Stress is reduced about $210 \mathrm{KN} / \mathrm{m}^{2}$ (figure 4 right). In this case similar behaviour is found when train travels from ballast track to slab track.

In both cases maximum stresses are under allowable limits for ballast. However these values go down or go up approximately 3,2 times higher in ballast track than slab track. This difference makes these point really problematic along the tracks.

Difference track superstructure properties and underlying layers properties from one point to other are important factors which lead to produce these great stresses differences from one point to another. This difference will also affect to ballast wear in these zones.

Fig. 8 - Continuous support in the boundary limit between slab track and ballasted 


\section{track (Sañudo, Markine et al. 2014).}

\subsection{Positioning of the supports in railway superstructures}

Possible solutions for a transition zone were investigated in (Sañudo, Markine et al. 2014)(Sañudo, Markine et al. 2011), additional sleepers, longer rails, pads with different stiffness. Figures 6 and 7 show other simulations carried out by authors in order to check the viability of possible solutions to make a gradual change in vertical displacements and stresses at these points between slab track and ballast track.

Positioning the supports immediately before and after the transition zone was an important variable (see figure 8). However, it has not been until now that an alternative positioning to those used in these previous studies has been evaluated (figure 1). When the current analysis (figures 3 to 4 ) is compared with others (figure 6 to 7) and (figure 8), (Sañudo, Markine et al. 2014), it leads to the conclusion that the positioning of supports separately has a positive effect by avoiding the generation of sudden impacts on both types of infrastructure in the separation zone.

\section{CONCLUSIONS}

The results of this research have found to some interesting conclusions. The zones located between slab track and ballasted track have a similar behavior for vertical displacements and similar when we focus on vertical stresses. Simulations showed that train travel direction has low influence in the track behaviour between slab and ballast area. Small increases in transient vertical displacements have found in the ballast side for both running directions (figure 3) and another slightly increase in transient vertical stresses in slab side for both travel directions (figure 4). However, additional comparisons between different positions of track supports at this points have also been made.

Results have shown that the positioning of the supports used in the analysis is better than the positioning used in others analysis (figures 5-8) and the set-up shown in figure 1 is recommended for future construction of railway superstructure in transition zones. In spite of the small differences found when considering the train running direction, the values were still within the established limits in both directions.

Further studies have to focus on fatigue analysis in a long term in order to detect hanging sleepers in these areas.

\section{REFERENCES}

ESVELD, C. (2001). Modern railway track. Second edition. Netherlands.

KOK, A. W. M. (1995). Lumped pulses and discrete displacements. Doct. Thesis, Delft University press, Delft(500): 1000.

LI, D. AND D. DAVIS (2005). Transition of railroad bridge approaches. Journal of Geotechnical and Geoenvironmental Engineering 131(11): 1392-1398.

LICHTBERGER, B. (2011). Manual de vía, Eurailpress, DVV Media Group. 
NAMURA, A. AND T. SUZUKI (2007). Evaluation of countermeasures against differential settlement at track transitions. Quarterly Report of RTRI 48(3): 176-182.

NASARRE, J. (2007). transiciones obra de paso-terraplén los bloques técnicos en las vías ferroviarias. proyecto y conservación, Fundacion Caminos de Hierro.

PAIXAO, A., E. FORTUNATO AND R. CALÇADA (2013). Design and construction of backfills for railway track transition zones. Proceedings of the Institution of Mechanical Engineers, Part F: Journal of Rail and Rapid Transit.

READ, D. AND D. LI (;2006). Design of track transitions. TCRP Research Results Digest(;79).

SAÑUDO,R. (2013). Optimización en el diseño de zonas de transición en vías de alta velocidad usando métodos numéricos. PhD Dissertation., Universidad de Cantabria.

SAÑUDO, R., DELL'OLIO, L., CASADO, J. A., CARRASCAL, I. A., AND DIEGO, S. (2016). Track transitions in railways: A review. Construction and Building Materials, 112, 140-157.

SAÑUDO, R., V. MARKINE AND L. DELL'OLIO (2011). Improving Track Transitions of High-Speed Lines. Proceedings of the Thirteenth International Conference on Civil, Structural and Environmental Engineering Computing. B. H. V. T. a. Y. Tsompanakis. Creta Greece: 15.

SAÑUDO, R., MARKINE, V., AND DELL'OLIO, L. (2014). A Numerical study on improvement of track transitions by modifying superstructure elements. The Ninth International Conference on Engineering Computational Technology. Naples, Italy 2-5 September 2014. ECT-17.

ZIENKIEWICZ AND R. L. TAYLOR (1977). The finite element method, McGraw-hill London. 